\title{
Undergraduate Tutorial System Based on Game Model
}

\author{
ZHANG Heng-wei \\ Zhengzhou Institute of Information Science and Technology, \\ Zhengzhou 450001, China, \\ Email: hjm_i_jbb@126.com
}

\begin{abstract}
Undergraduate tutorial system must be premised on fairness, which respect for the students' priority for tutor choosing. Different tutors have different experiences in paper guide, and senior tutors have high voice in thesis evaluation, therefore, senior tutors often become the object of contention for students, which formed an information asymmetry situation. However, the scarcity of senior teacher resources are often underutilized, resulting in the overall level of undergraduate thesis is not high. In this paper, using the signaling game model, analyzed the current configuration of undergraduate thesis tutor, and proposed corresponding improvement approaches. Finally, proposed some recommendations to enhance the quality of undergraduate thesis based on other system construction.
\end{abstract}

Keywords-Undergraduate Tutorial System; Information Asymmetry; Signaling Game Model

\section{INTRODUCTION}

The writing of undergraduate thesis is an important reflection of combining theory with practice through which students' abilities in mastering knowledge, analyzing problems and solving them can be examined and developed as the comprehensive practical teaching process[1]. Not only does the quality of undergraduate thesis is an important basis for measuring the teaching effect, but also it's the direct reflection of the quality of higher education[2]. However, the quality of undergraduate thesis recently declines significantly. Some scholars appeal to cancel the writing of undergraduate thesis. Aimed at the decline phenomenon, scholars have discussed a lot from many aspects. In [3], the authors hold the view that the main reason of the decline is formalism of school, lacking guidance of teachers and perfunctory handle of students. They pointed the key to enhance the quality of undergraduate thesis is to raise awareness of the importance of thesis writing and to make great efforts in the basic writing process. In [4], the author emphasized that due to employment pressure, bad practice effect and the lack of time and vigor, the undergraduate may not write the thesis seriously, which is the origin of the decline of thesis quality. He advised a practice mechanism should be established, by which employment can be guaranteed beforehand. Thus, students' attitude of thesis writing can be turned serious, enhancing the quality of undergraduate thesis in essence. In [5], authors suggested thesis writing should be conducted in advance. Besides, theme selection of the thesis should be objective. And the whole process should be supervised. There is no doubt that the above objectively analyzes the partial reason of the decline of thesis quality and also gives some effective advice. Nevertheless, in order to explore more factors to improve the thesis quality of undergraduate, we propose an undergraduate tutorial system based on game model. In this paper, we use the signaling game model to analyze the facts of undergraduate thesis.

\section{FUndAMENTAL ASSUMPTIONS AND THE GENERAL MODEL}

Now we make the following fundamental assumptions for the subsequent analysis.

Assumption 1: There are two types of the undergraduates. One type is good students that indicate whom with good foundation and the right attitude to the thesis writing, that really hope to write brilliant thesis(represented by GS), while the other type is bad students that indicate whom with poor foundation, who only want the thesis passed(represented by BS). The probability of each type is $1 / 2$.

Assumption 2: There are two types of the tutors. One indicates the senior tutors who are of rich experience and authoritative discourse power, and the other indicates those who lack experience. And the two types are represented by ST and JT respectively. The quantity of the senior tutors is less, which is in accordance with the general colleges.

Assumption 3: Types of the students are private information. Though types of students can be reflected by their academic achievement to a certain extent, there are so many students that tutors teaching a certain course cannot classify the right students' types. On the contrary, types of tutors are the common information for the students.

Assumption 4: Students' payoffs of completing the thesis consist of the positive effectiveness from thesis's scores and the negative effectiveness from the cost of thesis writing. The cost and effectiveness for tutors of different types are different in directing the students of different types, the cost and effectiveness for students of different types are also different under the direction of the tutors of different types, because of which there is a need to make a detailed assumption, as Tab.1 and Tab. 2 shows: 
TABLE I. COST AND EFFECTIVENESS FOR STUDENTS OF DIFFERENT TYPES TO COMPLETE A THESIS UNDER THE DIRECTION OF TUTORS OF DIFFERENT TYPES

\begin{tabular}{ccccc}
\hline & $\begin{array}{c}\text { Thesis } \\
\text { score }\end{array}$ & $\begin{array}{c}\text { Senior } \\
\text { tutor(ST) }\end{array}$ & $\begin{array}{c}\text { Junior } \\
\text { tutor(JT) }\end{array}$ & $\begin{array}{c}\text { Effectiveness } \\
\text { of thesis } \\
\text { score }\end{array}$ \\
\hline $\begin{array}{c}\text { Good } \\
\text { student(GS) }\end{array}$ & Brilliant & $C_{S T, b}^{G S}$ & $C_{J T, b}^{G S}$ & $U_{S, b}^{G S}$ \\
\cline { 2 - 5 } & Passed & $C_{S T, p}^{G S}$ & $C_{J T, p}^{G S}$ & $U_{S, p}^{G S}$ \\
\hline \multirow{2}{*}{$\begin{array}{c}\text { Bad } \\
\text { student(BS) }\end{array}$} & Brilliant & $C_{S T, b}^{B S}$ & $C_{J T, b}^{B S}$ & $U_{S, b}^{B S}$ \\
\cline { 2 - 5 } & Passed & $C_{S T, p}^{B S}$ & $C_{J T, p}^{B S}$ & $U_{S, p}^{B S}$ \\
\hline
\end{tabular}

According to the above the assumptions, we can draw the conclusion from Tab.1 $C_{S T, p}^{G S}<C_{J T, p}^{G S}<C_{J T, b}^{G S}$, $C_{S T, p}^{G S}<C_{S T, b}^{G S}<C_{J T, b}^{G S} \quad, \quad C_{S T, p}^{B S}<C_{J T, p}^{B S}<C_{J T, b}^{B S} \quad$, $C_{S T, p}^{B S}<C_{S T, b}^{B S}<C_{J T, b}^{B S}$. Besides, the cost of good students is less than the bad students'. The relationship of effectiveness of thesis scores is: $U_{S, p}^{G S}<U_{S, b}^{G S}, U_{S, p}^{B S}=U_{S, b}^{B S}$. For bad students, they only want the thesis passed, so the brilliant thesis is equal to the rightly passed thesis.

TABLE II. COST AND EFFECTIVENESS FOR TUTORS OF DIFFERENT TYPES TO DIRECT STUDENTS OF DIFFERENT TYPES TO COMPLETE THESIS

\begin{tabular}{ccccc}
\hline & $\begin{array}{c}\text { Thesis } \\
\text { score }\end{array}$ & $\begin{array}{c}\text { Bad } \\
\text { student(BS) }\end{array}$ & $\begin{array}{c}\text { Good } \\
\text { student(GS) }\end{array}$ & $\begin{array}{c}\text { Effectiveness } \\
\text { of thesis } \\
\text { score }\end{array}$ \\
\hline \multirow{2}{*}{$\begin{array}{c}\text { Senior } \\
\text { tutor(ST) }\end{array}$} & Brilliant & $C_{B S, b}^{S T}$ & $C_{G S, b}^{S T}$ & $U_{T, b}^{S T}$ \\
\cline { 2 - 5 } & Passed & $C_{B S, p}^{S T}$ & $C_{G S, p}^{S T}$ & $U_{T, p}^{S T}$ \\
\hline Junior & Brilliant & $C_{B S, b}^{J T}$ & $C_{G S, b}^{J T}$ & $U_{T, b}^{J T}$ \\
\hline
\end{tabular}

\begin{tabular}{|c|c|c|c|c|}
\hline tutor(JT) & Passed & $C_{B S, p}^{J T}$ & $C_{G S, p}^{J T}$ & $U_{T, p}^{J T}$ \\
\hline
\end{tabular}

Similarly, we can conclude from Tab. 2 based on the above assumptions: $C_{G S, p}^{S T}<C_{B S, p}^{S T}<C_{B S, b}^{S T}, C_{G S, p}^{S T}<C_{G S, b}^{S T}<C_{B S, b}^{S T}$, $C_{G S, p}^{J T}<C_{B S, p}^{J T}<C_{B S, b}^{J T}, C_{G S, p}^{J T}<C_{G S, b}^{J T}<C_{B S, b}^{J T}$. Besides, the cost of senior tutors is less than junior tutors'. The relationship of effectiveness of directing students is: $U_{T, p}^{S T}<U_{T, b}^{S T}$, $U_{T, p}^{J T}<U_{T, b}^{J T}$, and $U_{T, b}^{S T}<U_{T, b}^{J T}, \quad U_{T, p}^{S T}<U_{T, p}^{J T}$. For junior tutors, they may be much more delightful than senior tutors if the junior tutors can successfully direct students to complete thesis.

In order to embody the fairness of education, the undergraduate tutorial system tends to respect the rights of students, which entitles the student to select tutors before the tutor's selection to students. After the selection of the student to a certain tutor, the tutor selects students according to the number of students who can be directed. Thus, we can regard the above process as a game model of information asymmetry. Students (including good students and bad students) have advantage of information can release the corresponding signals $m_{1}$ and $m_{2}$. Under the above assumption, the senior tutors are the optimal selection for both good students and bad students. But the numbers of students who can be directed by senior tutors and the vigor of senior tutors is limited. The senior tutors must select some of those students. As the types of students are private information, it is difficult for senior tutors to select students for the maximum effectiveness. Therefore, we should design an undergraduate tutorial system to make the resources of the senior tutors fully utilized.

The game model is as follows:

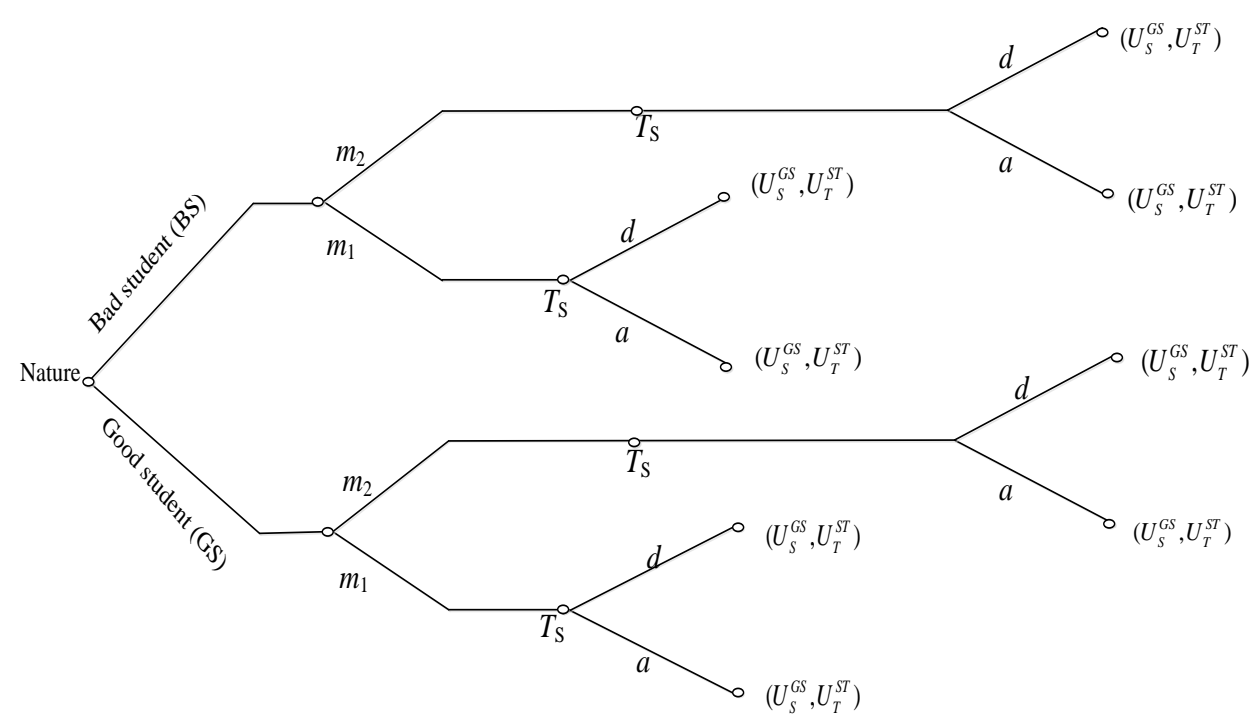

Fig. 1. Signaling Game Tree (The student selects the senior tutor.)

If the separating equilibrium of the above signaling game model exists, it means students release the signals which can reflect the real types of themselves; senior tutors accept good students and decline bad students. Then the undergraduate tutorial system is efficient, which can enhance the thesis quality under given conditions. 


\section{EFFICIENCY ANALYSIS OF THE EXISTING UNDERGRADUATE TUTORIAL SYSTEM}

There are generally two undergraduate tutorial systems for the undergraduate thesis: (1) After the selection of students to tutors, the tutors select students according to the number of students that can be directed. (2) Students select the thesis themes proposed by tutors beforehand to match the corresponding tutor, in which the same thesis theme cannot be selected by different students. Then if the number of students who select a certain tutor exceeds the limit, the tutor select several students from the all who select the tutor.

Apparently, the first system definitely is almost same with the above general game model. The second one seems fairer than the first, which is the completely anonymous two-way choice, meanwhile the interest of students is also considered. But it is hard to say the second one is more efficient than the first, because both players of the second system in the game would not make their effectiveness maximized to make decision. Further analysis shows there is no essential difference between the first system and the second, since students in the second system may only have additional cost for knowing who proposes the thesis theme through several approaches. Therefore, we only choose the first system to analyze the efficiency of existing undergraduate system.

Whether the above first system is efficient or not lies in the existence of separate equilibrium when choosing the system. If the separate equilibrium exists, the existing system is effective. Otherwise, the existing system should be improved.

Under the circumstance of the existing undergraduate tutorial system, in order to maximize his payoffs the student initially releases the signal beneficial to himself to be selected by the senior tutor. Then he shows the real type in the thesis writing and negotiates with the tutor. For instance, the bad student may ask the tutor to low the demand, since the tutor would like to make the compromise on the given conditions, which accord with the demand to maximize his own payoffs. The payoff of the tutor's selection to the player in signaling game model is showed in figure2.

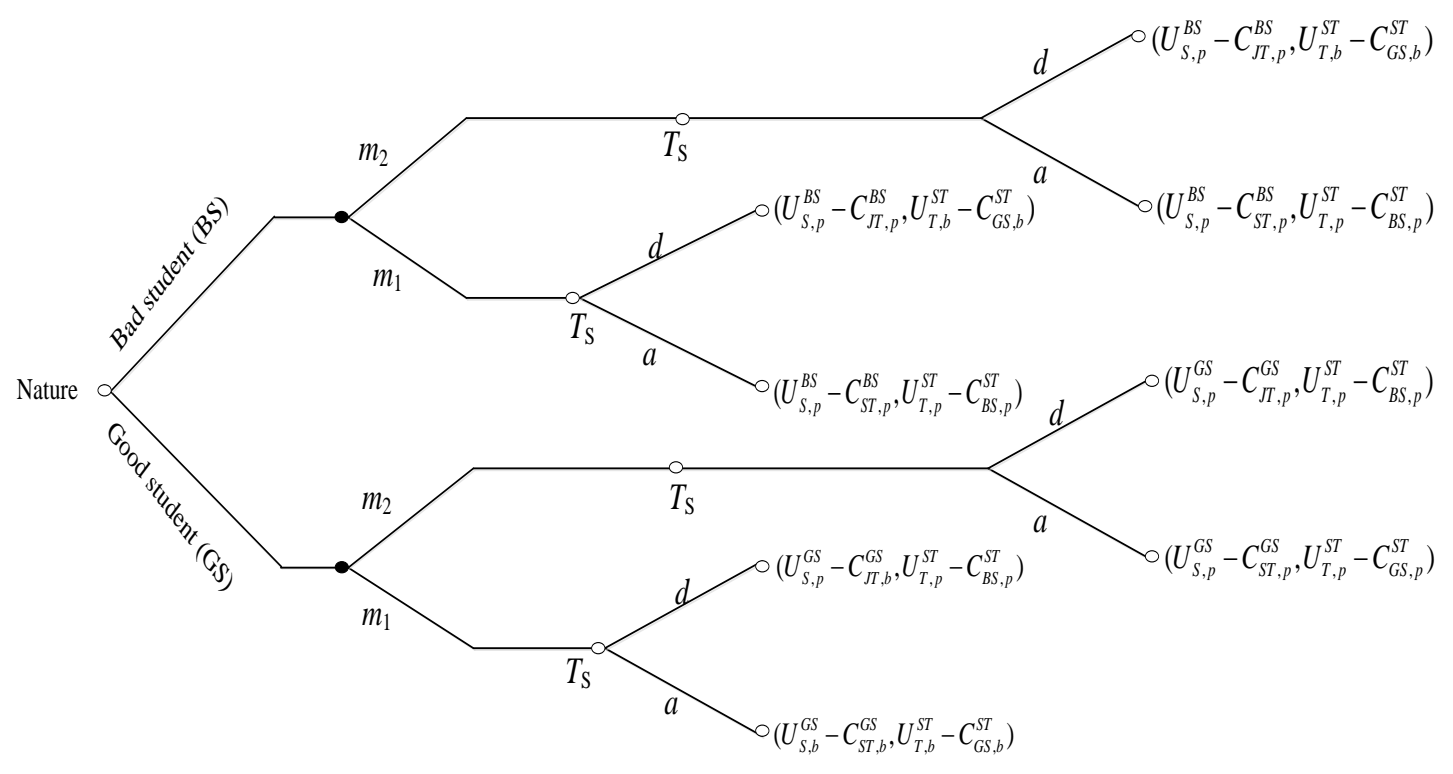

Fig. 2. Signaling Game Tree (The existing undergraduate thesis’s tutor allocation)

From figure2, there are only two results of separate equilibrium: (1) When $T_{S}$ receives the signal $m_{1}$, the senior tutor $T_{S}$ looks upon the student as a good one with the strategy selection a. When receiving the signal $m_{2}$, the senior tutor $T_{S}$ looks upon the student as a bad one with the strategy selection d. (2) When $T_{S}$ receives the signal $m_{2}$, the senior tutor looks upon the student as a good one with the strategy selection a. When receiving the signal $m_{1}$, the senior tutor $T_{S}$ looks upon the student as a bad one with the strategy selection d.

Now, we should ascertain whether the above two results are the real separate equilibrium. As for the result (1), given the judgment criterion of $T_{S}$, if the good student releases the signal $m_{1}$, the senior tutor $T_{S}$ will select the strategy a. In this situation, the whole payoff of the good student is $U_{S, b}^{G S}-C_{S T, b}^{G S}$, which is larger than the payoff $U_{S, p}^{G S}-C_{J T, p}^{G S}$ gotten by releasing the signal $m_{2}$, so the signal $m_{1}$ is the optimal selection for the good student. If the bad student releases the signal $m_{1}$, the senior tutor will select the strategy a, whose payoff is $U_{S, p}^{B S}-C_{S T, p}^{B S}$, which is larger than $U_{S, p}^{B S}-C_{J T, p}^{B S}$ gotten by releasing the signal $m_{2}$, so the signal $m_{1}$ is the optimal selection for the bad student. The above analysis indicates the result (1) is not the real separate equilibrium, which means all students will show themselves is good to the senior tutor.

Since the senior tutor usually would not select the one who boasts himself, the result (2) is unreasonable. Similarly, we analyze the result (2) and then can conclude both good student 
and bad student would release the signal $m_{2}$ to indicate themselves is bad. So the result (2) is also not the real separate equilibrium.

As the above analysis shows, the existing undergraduate tutorial system is not really reasonable, which cannot make the players including students and tutors maximize their payoffs. All students indicate themselves is a good one to the senior tutor. Once the bad student is selected by the senior tutor, he would ask the tutor to reduce requirements. Thus, the bad student maximizes his payoff, but the rare brilliant resources of the senior tutor are greatly wasted, which decline the quality of the undergraduate thesis.

\section{AN IMPROVEMENT IN THE UNDERGRADUATE TUTORIAL SYSTEM}

The main reason why the separate equilibrium cannot be formed in the general game model of the existing undergraduate tutorial system is that the bad student knows once he is selected by the senior tutor, he can ask for the tutor to reduce the thesis's requirements. And the tutor is also willing to modify the requirement. If not, the payoff of the senior tutor may be damaged much more. Therefore, if we convince the senior tutor that the good student or the bad student is required to write the brilliant thesis, thus, with the adjustment of the payoff when selecting the tutors, the bad student may not select the senior tutor, resulting in the separate equilibrium.

Now, we analyze the efficiency of the undergraduate tutorial system giving the tutor the convincing that thesis writing must be brilliant. Due to the authentic convincing, the bad student must cost $C_{S T, b}^{B S}$ larger than previous cost to complete a piece of brilliant thesis. Meanwhile, the tutor must cost $C_{B S, b}^{S T}$ which is also larger than the previous one. Payoff of the tutor's selection to the players in signaling game model is showed in figure3.

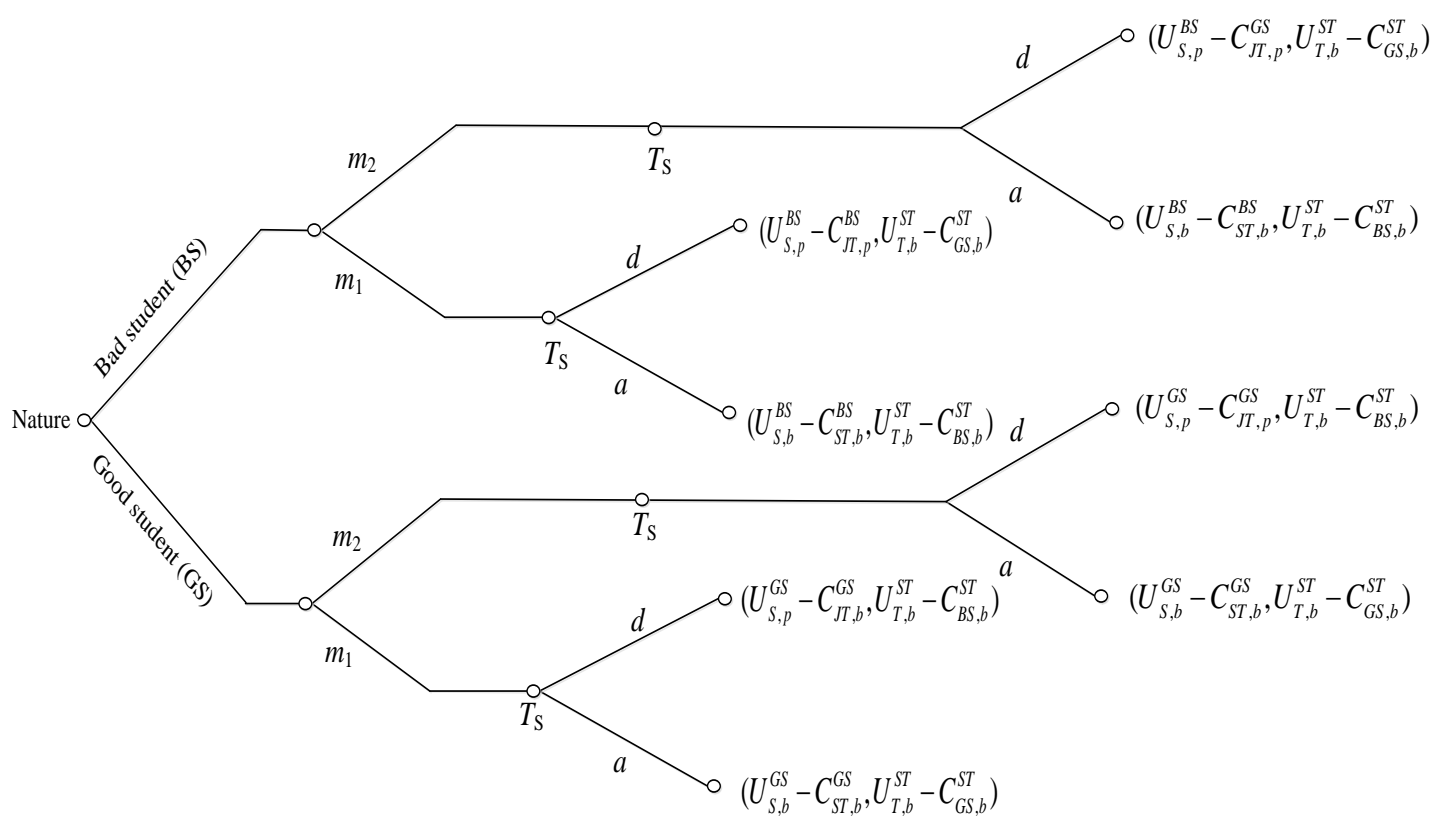

Fig. 3. Signaling Game Tree (The improved undergraduate thesis’s tutor allocation)

Similarly, as figure3 shows, there are only two results of separate equilibrium: (1) When $T_{S}$ receives the signal $m_{1}$, the senior tutor $T_{S}$ looks upon the student as a good one with the strategy selection a. When receiving the signal $m_{2}$, the senior tutor $T_{S}$ looks upon the student as a bad one with the strategy selection $d$. (2) When $T_{S}$ receives the signal $m_{2}$, the senior tutor looks upon the student as a good one with the strategy selection a. When receiving the signal $m_{1}$, the senior tutor $T_{S}$ looks upon the student as a bad one with the strategy selection $\mathrm{d}$.

Now, we should ascertain whether the above two results are the real separate equilibrium. As for the result (1), given the judgment criterion of $T_{S}$, if the good student releases the signal $m_{1}$, the senior tutor $T_{S}$ will select the strategy a. In this situation, the whole payoff of the good student is $U_{S, b}^{G S}-C_{S T, b}^{G S}$, which is larger than the payoff $U_{S, p}^{G S}-C_{J T, p}^{G S}$ gotten by releasing the signal $m_{2}$, so the signal $m_{1}$ is the optimal selection for the good student. If the bad student releases the signal $m_{1}$, the senior tutor will select the strategy a, whose payoff is $U_{S, p}^{B S}-C_{S T, p}^{B S}$, which is smaller than $U_{S, p}^{B S}-C_{J T, p}^{B S}$ gotten by releasing the signal $m_{2}$, so the signal $m_{2}$ is the optimal selection for the bad student. The above analysis indicates the result (1) is the real separate equilibrium, 
which means all students show their real type to the senior tutor.

For the result (2), it is also a separate equilibrium that the good student declare himself the bad one and the bad student declares himself the good one, which is scarcely existed in the real scene.

\section{CONCLUSION}

In this paper, the efficiency analysis of the existing undergraduate tutorial systems based on signaling game model shows the unreasonable results. Then we make a modification to improve the undergraduate tutorial system. Obviously, we give the senior tutor a convincing that the thesis writing must be brilliant, so separate equilibrium can be formed in the previous general signal game model. Both the good student and the bad student reflect their real type to the senior tutor, which results in the full utilization of the rare brilliant resources and can enhance the quality of the undergraduate thesis. Therefore, the improvement proposed in this paper is efficient.

\section{REFERENCES}

[1] Qiao Jun, Men Qing-ling. Some thought of improving the quality of undergraduate course graduation thesis[J]. EDUCATION EXPLORATION. 2011, Serial No. 243.

[2] Xu Hua-dong, Shen Mei-hua. Thought of guiding undergraduate course graduation design[J]. Educator.2013(9):64.

[3] Wang Jian, Lan Yu-jie, Wang Shao-feng. The route choice of enhancing the quality of the university undergraduate course graduation thesis[J]. Journal of Fuyang Teachers College(Social Science). 2011, No.4.

[4] Kang Hong-mei. The problem existing in the undergraduate course graduation thesis, causes and coping strategies[J]. CAREER HORIZON. 2014.02.

[5] Yang Ze-lin, Geng Guang-hua. Research on the current quality problems of the undergraduate course graduation thesis and efficient improved strategies[J]. Education and Vocation. 2012, (27):184-185. 